Article

\title{
Cutaneous Metastasis from Colorectal Cancer: Making Light on an Unusual and Misdiagnosed Event
}

\author{
Paola Parente ${ }^{1, *(\mathbb{D})}$, Davide Ciardiello ${ }^{2,3}$, Luca Reggiani Bonetti ${ }^{4}$, Vincenzo Famiglietti ${ }^{2}$, Gerardo Cazzato ${ }^{5}(\mathbb{D}$, \\ Stefania Caramaschi ${ }^{4}$, Vito Attino ${ }^{1}$, Diego Urbano ${ }^{1}$, Giuseppe Di Maggio ${ }^{1}$ and Giuseppe Ingravallo ${ }^{5}$ \\ 1 Pathology Unit, Fondazione IRCCS Ospedale Casa Sollievo della Sofferenza, \\ 71013 San Giovanni Rotondo, Italy; v.attino@operapadrepio.it (V.A.); urbediego@libero.it (D.U.); \\ giuseppedimaggio12@yahoo.it (G.D.M.) \\ 2 Oncologia Medica, Dipartimento di Medicina di Precisione, Università degli Studi della Campania "Luigi \\ Vanvitelli", 80138 Napoli, Italy; davideciardiello@yahoo.it (D.C.); vincenzo.famiglietti@yahoo.it (V.F.) \\ 3 Unità di Oncologia, Fondazione IRCCS Ospedale Casa Sollievo della Sofferenza, \\ 71013 San Giovanni Rotondo, Italy \\ 4 Department of Medical and Surgical Sciences for Children and Adults, University of Modena and Reggio \\ Emilia-AOU Policlinico of Modena, 41124 Modena, Italy; luca.reggianibonetti@unimore.it (L.R.B.); \\ stefania.caramaschi@unimore.it (S.C.) \\ 5 Pathology Unit, Department of Organ Transplantation and Emergency (DETO), University Hospital of Bari, \\ 70124 Bari, Italy; gerycazzato@hotmail.it (G.C.); giuseppe.ingravallo@uniba.it (G.I.) \\ * Correspondence: paolaparente77@gmail.com
}

check for updates

Citation: Parente, P.; Ciardiello, D.; Reggiani Bonetti, L.; Famiglietti, V.; Cazzato, G.; Caramaschi, S.; Attino, V.; Urbano, D.; Di Maggio, G.;

Ingravallo, G. Cutaneous Metastasis from Colorectal Cancer: Making Light on an Unusual and Misdiagnosed Event. Life 2021, 11, 954. https:// doi.org/10.3390/life11090954

Academic Editor: Chang-Hun Huh

Received: 18 July 2021

Accepted: 9 September 2021

Published: 11 September 2021

Publisher's Note: MDPI stays neutral with regard to jurisdictional claims in published maps and institutional affiliations.

Copyright: (c) 2021 by the authors. Licensee MDPI, Basel, Switzerland. This article is an open access article distributed under the terms and conditions of the Creative Commons Attribution (CC BY) license (https:/ / creativecommons.org/licenses/by/ $4.0 /)$.

\begin{abstract}
Cutaneous metastasis from solid tumors is a rare event and usually represents a late occurrence in the natural history of an advanced visceral malignancy. Rarely, cutaneous metastasis has been described in colorectal cancer patients. The most frequent cutaneous site of colorectal metastasis is the surgical scar in the abdomen following the removal of the primary malignancy, followed by the extremities, perineum, head, neck, and penis. Metastases to the thigh and back of the trunk are anecdotical. Dermatological diagnosis of cutaneous metastasis can be quite complex, especially in unusual sites, such as in the facial skin or thorax and in cases of single cutaneous lesions since metastasis from colorectal cancer is not usually the first clinical hypothesis, leading to misdiagnosis. To date, due to the rarity of cutaneous metastasis from colorectal cancer, little evidence, most of which is based on case reports and very small case series, is currently available. Therefore, a better understanding of the clinic-pathological characteristics of this unusual metastatic site represents an unmet clinical need. We present a large series of 29 cutaneous metastases from colorectal cancer with particular concerns regarding anatomic localization and the time of onset with respect to primitive colorectal cancer and visceral metastases.
\end{abstract}

Keywords: adenocarcinoma; colorectal cancer; cutaneous metastasis; intestinal cancer; skin tumors; visceral metastases

\section{Introduction}

Cutaneous metastasis from solid tumors is rare and occurs in $0.7 \%$ to $5 \%$ of all cancers [1]. Cutaneous metastasis generally represents a late event of an advanced visceral malignancy and occurs with greater frequency in melanoma and lung carcinoma, followed by kidney and ovary cancer [1,2]. Cutaneous metastasis has rarely been described in hepato-biliary malignancies [3].

Colorectal cancer (CRC) typically metastasizes to the lymph nodes, lung, liver, and peritoneum, and the development of skin metastasis from CRC is uncommon $(2.3 \%$ to $6 \%$ [2]. The most frequent cutaneous site of CRC metastasis is the surgical scar in the abdomen resulting from the removal of the primary malignancy, followed by the extremities, perineum, head, neck, and penis. An atypical localization is the umbilical region also 
knows as 'Sister Mary Joseph nodule' [4]. Metastases to the thigh and back of the trunk are anecdotical [4,5].

The literature reports two distinct clinical patterns of skin metastases from CRC: the first showing multiple visceral and cutaneous metastases at the time of presentation and the second developing cutaneous metastases during the follow-up, after the resection of the primary tumor [6].

Several clinical presentations have been described in CRC cutaneous metastasis, the most frequent being ulcers, papules, nodules, plaques, and rapidly growing painless dermal or subcutaneous nodules with intact overlying epidermis or mimic inflammatory dermatosis [5].

The diagnosis of cutaneous metastasis can be quite complex, especially in unusual sites, such as in the facial skin or thorax, and in cases of single cutaneous lesions, since metastasis from CRC usually is not the first clinical hypothesis, mostly due to the absence of adequate clinical context reporting CRC notice.

To date, due to the rarity of cutaneous metastasis from CRC, little evidence, most of which is represented by case reports and very small case series, is currently available. Therefore, a better understanding of the clinic-pathological characteristics of this unusual metastatic site represents an unmet clinical need. We have retrospectively analyzed a large series of 29 cutaneous metastases from CRC and their epidemiological and clinical features with particular concerns regarding anatomic localization and the time of onset with respect to the primitive CRC and visceral metastases.

\section{Materials and Methods}

We retrospectively collected 29 cases of cutaneous metastasis from CRC from the electronic pathology archives at the Unit of Pathology, Fondazione IRCCS Ospedale Casa Sollievo della Sofferenza, San Giovanni Rotondo, Italy, at the Unit of Pathology, University of Bari, Italy, and at the Unit of Pathology, Modena, Italy, between 2004 and 2020.

All information regarding human tissue was managed using anonymous numerical codes, and all samples were handled in compliance with the Helsinki Declaration (https:/ / www.wma.net/what-we-do/medical-ethics/declaration-of-helsinki/ (accessed on 10 September 2021)).

\section{Clinic-Pathologic Evaluation}

The following data were collected: demographic data (age at diagnosis of skin metastasis, gender), anatomic localization, number (single/multiple) and gross findings (size and morphologic features) of the lesions, clinical hypothesis of the entity (primitive skin tumour, dermatosis, metastasis), time of onset with respect to CRC diagnosis (synchronous if $\leq 12$ months and metachronous if $>12$ months from CRC diagnosis, respectively), time of onset with respect to visceral metastases (synchronous if $\leq 12$ months and metachronous if $>12$ months from visceral metastases diagnosis and 'previous' if skin metastases arose before visceral metastases), histotype according to World Health Organization (WHO) Classification of Digestive System Tumours, 5th edition, 2019 [7], and tumor staging based on surgery according to the Union for International Cancer Control/American Joint Committee on Cancer (UICC/AJCC) 8th edition [8] for primitive CRC (Table 1).

The morphology of the collected tumor samples was revised, and new sections were microtome cut and stained with Haematoxylin and Eosin (H\&E) when necessary, initially by the submitting center and subsequently by the central collection center (Fondazione IRCCS Ospedale Casa Sollievo della Sofferenza, San Giovanni Rotondo). The following histological parameters of cutaneous metastases were collected: (i) localization of the metastasis (dermal, ipodermal, dermo-ipodermal), (ii)differentiation grading (based on percentage of glandular component according to World Health Organization (WHO) Classification of Digestive System Tumours, 5th edition, 2019 [7]), and (iii) additional morphological findings (squamous component; mucinous component; signet ring component) (Table 2). 
Table 1. Clinic-pathological characteristics of primitive CRC. NOS: not otherwise specified (according to World Health Organization (WHO) Classification of Digestive System Tumours, 5th edition, 2019 [7]); NE: not evaluable.

\begin{tabular}{|c|c|c|c|c|c|c|}
\hline Case & Age (Years) & Gender & $\begin{array}{l}\text { Tumor } \\
\text { Location }\end{array}$ & Histotype & Grading & $\begin{array}{c}\text { Pathological } \\
\text { Stage } \\
\text { UICC } 2017\end{array}$ \\
\hline 1 & 70 & Male & Left colon & Adenosquamous & G3 & pT4a pN2a \\
\hline 2 & 41 & Male & Right colon & $\begin{array}{l}\text { Signet ring; } \\
\text { mucinous }\end{array}$ & G3 & NE \\
\hline 3 & 60 & Male & Left colon & NOS & G3 & pT4a pN2b \\
\hline 4 & 70 & Female & Right colon & NOS & G2 & pT3 pN0 \\
\hline 5 & 85 & Male & Left colon & NOS & G3 & pT4a pN1b \\
\hline 6 & 48 & Male & Right colon & NOS & G2 & pT4a pN0 \\
\hline 7 & 76 & Female & Right colon & NOS & G2 & pT4a pN1 \\
\hline 8 & 74 & Male & Left colon & $\begin{array}{l}\text { NOS with } \\
\text { mucinous } \\
\text { component }\end{array}$ & NE & pT3 pN0 \\
\hline 9 & 70 & Male & Right colon & NOS & $\mathrm{NE}$ & NE \\
\hline 10 & 74 & Male & Right colon & NOS & NE & NE \\
\hline 11 & 84 & Female & Left colon & NOS & G2 & pT3 pN0 \\
\hline 12 & 63 & Male & Left colon & NOS & $\mathrm{NE}$ & NE \\
\hline 13 & 62 & Male & Rectum & NOS & $\mathrm{NE}$ & $\mathrm{NE}$ \\
\hline 14 & 63 & Male & Rectum & NOS & $\mathrm{NE}$ & pT3 pN2 \\
\hline 15 & 69 & Female & Anus & NOS & $\mathrm{NE}$ & NE \\
\hline 16 & 74 & Male & Right colon & Adenosquamous & G3 & pT4a pN2b \\
\hline 17 & 76 & Male & Rectum & NOS & G2 & pT3 pN0 \\
\hline 18 & 89 & Female & Right colon & NOS & G3 & pT3 pN1p M1 \\
\hline 19 & 79 & Male & Right colon & NOS & G3 & pT4 pN1b M1 \\
\hline 20 & 73 & Male & Sigma-rectum & NOS & G2 & pT3 N1b \\
\hline 21 & 69 & Female & $\begin{array}{l}\text { Transverse } \\
\text { colon }\end{array}$ & NOS & G2 & pT3 N1b M1 \\
\hline 22 & 77 & Male & Right colon & NOS & G2 & pT4a N2 \\
\hline 23 & 80 & Male & Rectum & NOS & G3 & pT4 N0 \\
\hline 24 & 79 & Female & Right colon & NOS & G3 & $\mathrm{NE}$ \\
\hline 25 & 75 & Male & Right colon & $\begin{array}{l}\text { Signet ring; } \\
\text { mucinous }\end{array}$ & G3 & pT4 N2 M1 \\
\hline 26 & 66 & Female & Right colon & $\begin{array}{l}\text { Signet ring; } \\
\text { mucinous }\end{array}$ & G3 & pT4 N2 \\
\hline 27 & 83 & Male & Left colon & NOS & G3 & pT3 N1 \\
\hline 28 & 85 & Male & Left colon & NOS & G3 & pT1 N0 \\
\hline 29 & 83 & Female & Left colon & NOS & G2 & $\mathrm{NE}$ \\
\hline
\end{tabular}

Table 2. Clinic-pathological characteristics of the skin CRC metastases. CM: centimeters; NE: not evaluable; ADK NOS: adenocarcinoma not otherwise specified [7].

\begin{tabular}{|c|c|c|c|c|c|c|}
\hline Case & Macroscopy & $\begin{array}{l}\text { Size } \\
(\mathrm{CM})\end{array}$ & $\begin{array}{c}\text { Clinical } \\
\text { Hypothesis }\end{array}$ & Localization & $\begin{array}{l}\text { Grading of } \\
\text { Skin } \\
\text { Metastasis } \\
\text { (Glandular } \\
\text { Component) }\end{array}$ & $\begin{array}{c}\text { Additional } \\
\text { Morphological } \\
\text { Findings of } \\
\text { Skin } \\
\text { Metastasis [7] }\end{array}$ \\
\hline 1 & Nodular lesion & 2 & Epithelioma & $\begin{array}{c}\text { Dermo- } \\
\text { ipodermal }\end{array}$ & G3 & $\begin{array}{l}\text { Keratinizant- } \\
\text { squamous } \\
\text { component }\end{array}$ \\
\hline 2 & Nodular lesion & 1.3 & Metastasis & $\begin{array}{c}\text { Dermo- } \\
\text { ipodermal }\end{array}$ & G3 & ADK; NOS \\
\hline
\end{tabular}


Table 2. Cont.

\begin{tabular}{|c|c|c|c|c|c|c|}
\hline Case & Macroscopy & $\begin{array}{l}\text { Size } \\
(\mathrm{CM})\end{array}$ & $\begin{array}{c}\text { Clinical } \\
\text { Hypothesis }\end{array}$ & Localization & $\begin{array}{l}\text { Grading of } \\
\text { Skin } \\
\text { Metastasis } \\
\text { (Glandular } \\
\text { Component) }\end{array}$ & $\begin{array}{l}\text { Additional } \\
\text { Morphological } \\
\text { Findings of } \\
\text { Skin } \\
\text { Metastasis [7] }\end{array}$ \\
\hline 3 & Nodular lesion & 3 & Metastasis & $\begin{array}{c}\text { Dermo- } \\
\text { ipodermal }\end{array}$ & G3 & $\begin{array}{l}\text { Mucinous; } \\
\text { signet ring }\end{array}$ \\
\hline 4 & $\begin{array}{l}\text { Vegetant } \\
\text { ulcerating } \\
\text { lesion }\end{array}$ & 8 & Metastasis & $\begin{array}{l}\text { Dermo- } \\
\text { ipodermal }\end{array}$ & G1 & ADK; NOS \\
\hline 5 & $\begin{array}{l}\text { Ipodermal } \\
\text { cystic lesion }\end{array}$ & 2.5 & NE & $\begin{array}{c}\text { Dermo- } \\
\text { ipodermal }\end{array}$ & G3 & ADK; NOS \\
\hline 6 & $\begin{array}{l}\text { Vegetant } \\
\text { ulcerating } \\
\text { lesion }\end{array}$ & 1 & NE & $\begin{array}{l}\text { Dermo- } \\
\text { ipodermal }\end{array}$ & G2 & ADK; NOS \\
\hline 7 & Nodular lesion & 2.5 & $\mathrm{NE}$ & $\begin{array}{c}\text { Dermo- } \\
\text { ipodermal }\end{array}$ & G2 & ADK; NOS \\
\hline 8 & Nodular lesion & 1.3 & NE & $\begin{array}{l}\text { Dermo- } \\
\text { ipodermal }\end{array}$ & G1 & $\begin{array}{l}\text { Mucinous } \\
\text { component }\end{array}$ \\
\hline 9 & Nodular lesion & 0.4 & NE & $\begin{array}{l}\text { Dermo- } \\
\text { ipodermal }\end{array}$ & G3 & ADK; NOS \\
\hline 10 & Nodular lesion & 1 & Metastasis & $\begin{array}{l}\text { Dermo- } \\
\text { ipodermal }\end{array}$ & G1 & $\begin{array}{l}\text { Mucinous } \\
\text { component }\end{array}$ \\
\hline 11 & Nodular lesion & 0.7 & Metastasis & Dermal & G2 & ADK; NOS \\
\hline 12 & Nodular lesion & 0.6 & Metastasis & $\begin{array}{c}\text { Dermo- } \\
\text { ipodermal }\end{array}$ & G2 & ADK; NOS \\
\hline 13 & Nodular lesion & 1.5 & Metastasis & $\begin{array}{l}\text { Dermo- } \\
\text { ipodermal }\end{array}$ & G1 & ADK; NOS \\
\hline 14 & $\begin{array}{l}\text { Nodular } \\
\text { ulcerating } \\
\text { lesion }\end{array}$ & 2.5 & Metastasis & $\begin{array}{c}\text { Dermo- } \\
\text { ipodermal }\end{array}$ & G1 & ADK; NOS \\
\hline 15 & Nodular lesion & 8 & Metastasis & $\begin{array}{c}\text { Dermo- } \\
\text { ipodermal }\end{array}$ & G3 & $\begin{array}{l}\text { Mucinous } \\
\text { component }\end{array}$ \\
\hline 16 & Nodular lesion & 5 & Metastasis & $\begin{array}{l}\text { Dermo- } \\
\text { ipodermal }\end{array}$ & G3 & ADK; NOS \\
\hline 17 & Nodular lesion & 2.7 & Metastasis & $\begin{array}{l}\text { Dermo- } \\
\text { ipodermal }\end{array}$ & G2 & $\begin{array}{c}\text { Nonkeratinizant } \\
\text { squamous } \\
\text { component }\end{array}$ \\
\hline 18 & Nodular lesion & 0.8 & Adnexal tumor & $\begin{array}{c}\text { Dermo- } \\
\text { ipodermal }\end{array}$ & G3 & ADK; NOS \\
\hline 19 & Nodular lesion & 1.5 & Sebaceous cist & Dermal & G3 & ADK; NOS \\
\hline 20 & Nodular lesion & 1 & Metastasis & $\begin{array}{l}\text { Dermo- } \\
\text { ipodermal }\end{array}$ & G2 & ADK; NOS \\
\hline 21 & Nodular lesion & 2 & Metastasis & $\begin{array}{l}\text { Dermo- } \\
\text { ipodermal }\end{array}$ & G1 & ADK; NOS \\
\hline 22 & Nodular lesion & 5 & Metastasis & $\begin{array}{l}\text { Dermo- } \\
\text { ipodermal }\end{array}$ & G2 & ADK; NOS \\
\hline 23 & Nodular lesion & 2.2 & Metastasis & $\begin{array}{l}\text { Dermo- } \\
\text { ipodermal }\end{array}$ & G3 & ADK; NOS \\
\hline 24 & $\begin{array}{l}\text { Nodular } \\
\text { ulcerating } \\
\text { lesion }\end{array}$ & 1 & Epithelioma & $\begin{array}{c}\text { Dermo- } \\
\text { ipodermal }\end{array}$ & G3 & ADK; NOS \\
\hline 25 & Nodular lesion & 1.5 & Metastasis & $\begin{array}{l}\text { Dermo- } \\
\text { ipodermal }\end{array}$ & NV & Mucinous \\
\hline
\end{tabular}


Table 2. Cont.

\begin{tabular}{|c|c|c|c|c|c|c|}
\hline Case & Macroscopy & $\begin{array}{l}\text { Size } \\
(\mathrm{CM})\end{array}$ & $\begin{array}{c}\text { Clinical } \\
\text { Hypothesis }\end{array}$ & Localization & $\begin{array}{l}\text { Grading of } \\
\text { Skin } \\
\text { Metastasis } \\
\text { (Glandular } \\
\text { Component) }\end{array}$ & $\begin{array}{c}\text { Additional } \\
\text { Morphological } \\
\text { Findings of } \\
\text { Skin } \\
\text { Metastasis [7] }\end{array}$ \\
\hline 26 & Nodular lesion & 1 & Metastasis & $\begin{array}{c}\text { Dermo- } \\
\text { ipodermal }\end{array}$ & G3 & Mucinous \\
\hline 27 & Nodular lesion & 2.5 & Metastasis & $\begin{array}{l}\text { Dermo- } \\
\text { ipodermal }\end{array}$ & G3 & ADK; NOS \\
\hline 28 & $\begin{array}{c}\text { Vegetant } \\
\text { ulcerating } \\
\text { lesion }\end{array}$ & 2 & Metastasis & $\begin{array}{c}\text { Dermo- } \\
\text { ipodermal }\end{array}$ & G3 & ADK; NOS \\
\hline 29 & Nodular lesion & 3 & Metastasis & $\begin{array}{c}\text { Dermo- } \\
\text { ipodermal }\end{array}$ & G2 & ADK; NOS \\
\hline
\end{tabular}

\section{Results}

\subsection{Clinical Findings}

Of the 29 patients, the median age was 72 years of age (range 41-89); most of the patients were male (20 males, 9 females). Out of the reported cases, 20 out of 29 cases presented as a single skin lesion (70\%), 6 of which occurring in the abdomen $(6 / 20 ; 30 \%)$, 6 occurring in the thoracic skin $(6 / 20 ; 30 \%), 3$ occurring in the perineum $(3 / 20 ; 15 \%)$, and 5 occurring in the facial skin $(5 / 20 ; 25 \%)$. A total of 9 out of $29(30 \%)$ patients presented multiple skin lesions, 7 of which occurred in the abdomen $(7 / 9 ; 78 \%), 1$ of which occurred in the perineum $(1 / 9 ; 11 \%)$, and 1 of which occurred in the arm $(1 / 9 ; 11 \%)$. A total of 13 out of 29 cases ( $45 \%$ ) were localized in the abdominal skin; $6 / 29$ cases $(20 \%)$ were localized in the thoracic skin; $5 / 29$ cases $(17 \%)$ on facial skin; $4 / 29$ cases $(13 \%)$ were localized in the perineum; and $1 / 29$ case $(5 \%)$ was localized on the arm (Figure 1 ).

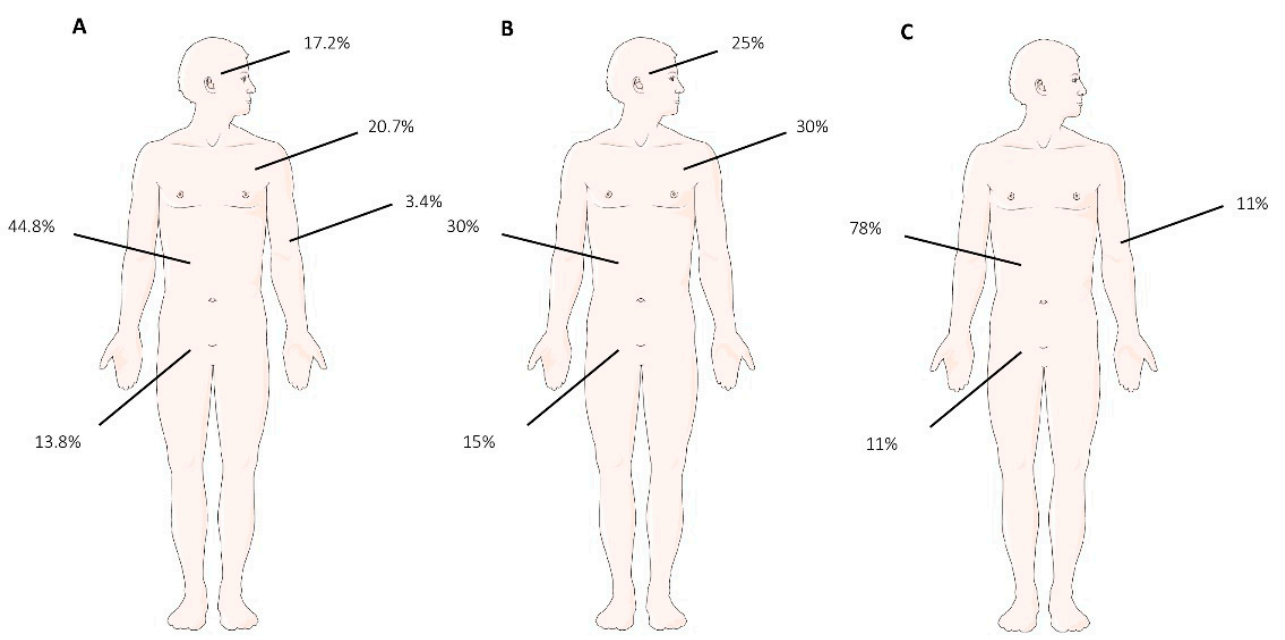

Figure 1. (A) Localization and percentage of cutaneous metastasis: abdomen 13/29 (44.8\%); thorax 6/29 (20.7\%); facial skin 5/29 (17.2\%); pelvis 4/29 (13.8\%); arm 1/29 (3.4\%). (B) Localization and percentage of single lesions: abdomen 6/20 (30\%); thorax 6/20 (30\%); facial skin 5/20 (25\%); pelvis $3 / 20$ (15\%). (C) Localization and percentage of multiple lesions: abdomen $7 / 9(30 \%)$, pelvis $1 / 29(11 \%)$, arm $1 / 9(11 \%)$.

The median size of the lesions was $2.3 \mathrm{~cm}$ (range 0.4-8) (Table 2). A total of 15 cases $(15 / 29,52 \%)$ were synchronous, and $14 / 29$ cases $(48 \%)$ were metachronous to CRC. In the synchronous metastases, 8/15 were located in the abdomen (53\%), 4/15 (26\%) were located in the thoracic skin, 2/15 (13\%) were located in the facial skin, and 1/15 (8\%) were located on the arm, respectively. In the metachronous metastases, 5/14 (36\%) were located 
in the abdomen, $2 / 14(14 \%)$ were located in the thoracic skin, $4 / 14(28 \%)$ were located in the perineum, and $3 / 14(22 \%)$ were located in the facial skin (Table 3$)$.

Table 3. Temporal correlation of cutaneous metastases with respect to CRC.

\begin{tabular}{cccc}
\hline Localization & Synchronous to CRC & Metachronous to CRC & Total \\
\hline Abdomen & 8 & 5 & 13 \\
Thorax & 4 & 2 & 6 \\
Facial Skin & 2 & 3 & 5 \\
Pelvis & 0 & 4 & 4 \\
Arm & 1 & 0 & 1 \\
& 15 & 14 & 29 \\
\hline
\end{tabular}

A total of $5 / 29$ cases $(17 \%)$ were metachronous to visceral metastases from CRC; $3 / 29$ cases $(10 \%)$ presented before, and $7 / 29$ cases $(24 \%)$ were synchronous to visceral metastases, respectively. In those that were synchronous with respect to visceral metastases, $2 / 7$ cases $(28.5 \%)$ were located in the abdomen, $2 / 7(28.5 \%)$ cases were located in the thoracic skin, $2 / 7(28.5 \%)$ cases were located in the perineum, and $1 / 7$ case $(15 \%)$ was located in the arm. In the metachronous lesions, $2 / 5$ cases $(40 \%)$ were located in the abdomen, $2 / 5$ cases (40\%) were located in the thorax, and $1 / 5(20 \%)$ was located in the facial skin. Interestingly, of the three cases arising before visceral metastases, one case was in the abdomen, one case was in the thoracic skin, and one case was in the facial skin. In $14 / 29$ cases $(49 \%)$, no data regarding visceral metastases were available (Table 4$)$.

Table 4. Temporal correlation of cutaneous metastases with respect to visceral metastasis from CRC. VM: visceral metastasis.

\begin{tabular}{ccccc}
\hline \multirow{2}{*}{ Localization } & $\begin{array}{c}\text { Synchronous to } \\
\text { VM }\end{array}$ & $\begin{array}{c}\text { Onset before to } \\
\text { VM }\end{array}$ & $\begin{array}{c}\text { Metachronous to } \\
\text { VM }\end{array}$ & Total \\
\hline Abdomen & 2 & 1 & 2 & 5 \\
Thorax & 2 & 1 & 2 & 5 \\
Facial Skin & 0 & 1 & 1 & 2 \\
Pelvis & 2 & 0 & 0 & 2 \\
Arm & 1 & 0 & 0 & 1 \\
& 7 & 3 & 5 & 15 \\
\hline
\end{tabular}

Based on presentation and according to the medical history, twenty cases $(20 / 29,70 \%)$ were clinically referred as suspected of CRC metastases; instead, 4/29 cases (13\%) were submitted as primitive cutaneous tumors. In 5/29 cases (17\%), no clinical hypothesis was referred (Table 2). Regarding the clinical presentation, twenty-four cases $(83 \%)$ presented macroscopically as 'nodular lesions'; 4/29 (14\%) presented as 'vegetant' lesions, and $1 / 29$ case $(3 \%)$ appeared as an ipodermal cystic lesion. A total of $6 / 29$ lesions $(20 \%)$ were ulcerated. In $21 / 29$ cases $(72 \%)$, we were able to acquire the pathological stage of CRC, whereas in $8 / 29$ cases $(28 \%)$, we were not able to determine the pathological stage of CRC, as the laboratory services did not inform us. In $13 / 29$ patients (45\%), primary CRC was located in right colon; in $9 / 29$ cases (31\%), it was located in the left colon, in 5/29 (17\%), it was located in the rectum, and in $1 / 29$ cases, (3.5\%) it was located in the transverse colon, and in $1 / 29$ cases $(3.5 \%)$, it was located in the anus (Table 1$)$.

\subsection{Histopathological Findings}

Morphologic findings of the cutaneous metastases are described in Table 2. Twentyseven cases (93\%) presented as dermal/ipodermal lesions, and two cases (7\%) were dermalconfined lesions. For 22 patients $(76 \%)$, we were able to obtain a histological surgical sample of primitive CRC. Of them, $9 / 22$ cases (40\%) were low-grade adenocarcinoma (i.e., G1-G2 sec WHO 2019), and 13/22 tumors (60\%) were high grade adenocarcinoma (i.e., G3 sec WHO 2019). Moreover, for 28 tumor samples, we could assign grading to the 
cutaneous metastases. Of them, 14/28 (50\%) were low-grade adenocarcinoma (i.e., G1-G2 sec WHO 2019), whereas 14/28 cases (50\%) were high-grade adenocarcinoma (i.e., G3 sec WHO 2019). In one case, we could not evaluate a glandular component (i.e., grading) due to the small size of the biopsy. In $6 / 29$ cases of the cutaneous samples, $(20 \%)$, we described a mucinous and/or signet ring neoplastic component, and in 2/29 (6\%), we were able to describe a squamous neoplastic component (Figure 2).

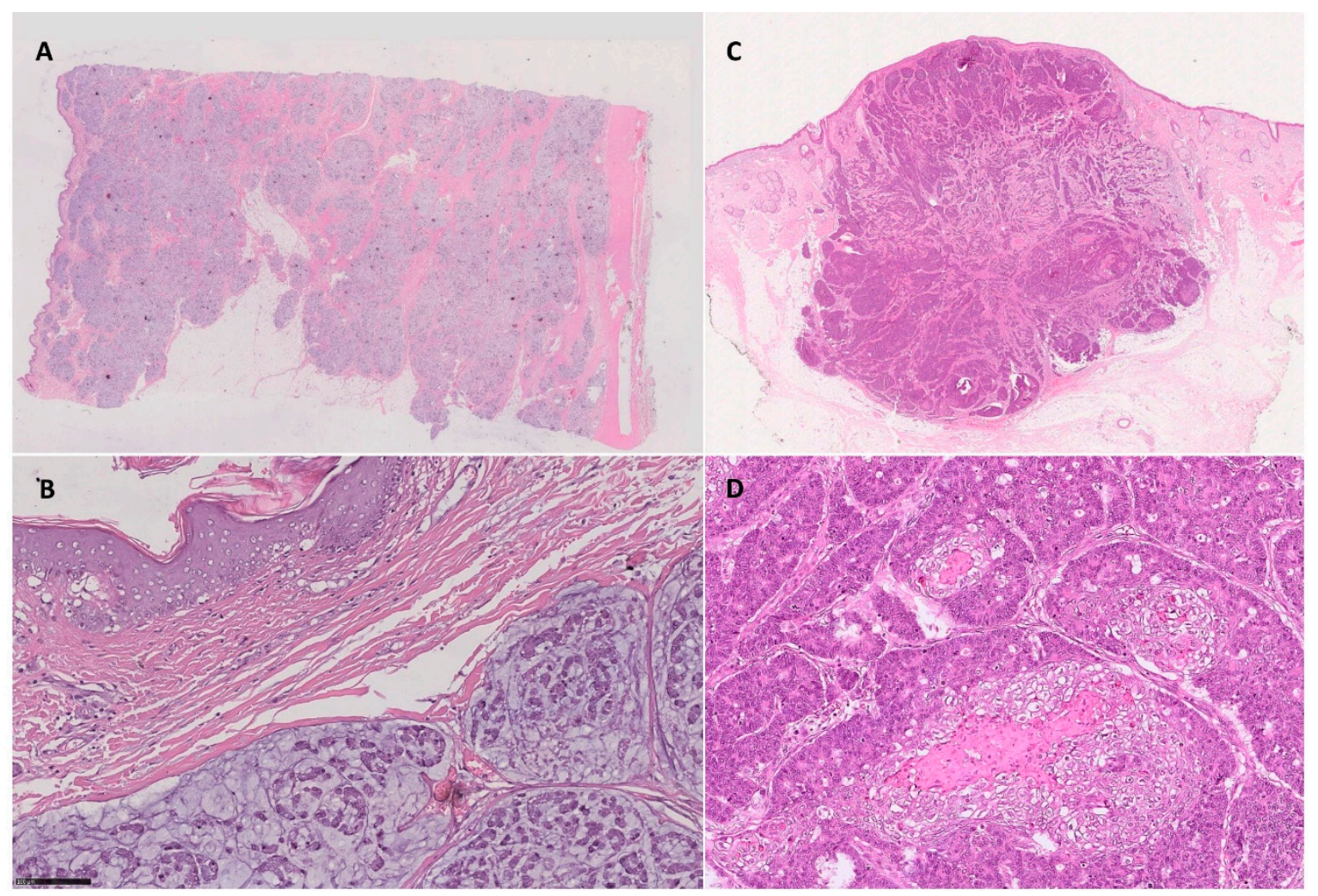

Figure 2. (A,B) Mucinous component in cutaneous metastasis from CRC ((A) H\&E 0.5X; (B) H\&E 25X). (C,D) Squamous component in facial skin metastasis from adenosquamous CRC ((C) H\&E 0.5X; (D) H\&E 20X).

The histotype comparison between primitive CRC and the skin metastases is reported in Table 5, based on WHO classification [7]. Twenty-two cases of the surgical resections were classified as NOS-CRC; in three cases, we observed a mucinous-signet ring histotype; in two cases, we described an adenosquamous (ASC) histotype; in one case, a mucinous histotype was described, and in one case, a mucinous component was described (i.e., mucinous component less than 30\%), respectively. All cases of skin metastases were classified as NOS-ADK; in five cases, we observed an additional mucinous component; in two cases, we observed a squamous component, and in the last one, a signet-ring-mucinous component was observed. In six out of eight skin metastases $(75 \%)$, we observed the same histotype in both the primitive and cutaneous metastases; in detail, we observed two cases with the ASC histotype and four cases with mucinous component. In one case, the mucinous component observed in the primitive CRC was not evaluable in the skin metastases; in one case, we observed a mucinous component in a metastasis not described in primitive CRC. 
Table 5. Comparison between the histology of the primary tumor and skin metastases. ADS: adenosquamous; NOS: not otherwise specified; ADK: adenocarcinoma.

\begin{tabular}{|c|c|c|}
\hline Case & $\begin{array}{c}\text { Primary Tumor Hystotype According } \\
\text { to WHO } 2019\end{array}$ & $\begin{array}{l}\text { Additional Morphological Findings } \\
\text { of Skin Metastasis }\end{array}$ \\
\hline 1 & ADS & Keratinizant squamous component \\
\hline 2 & Signet ring; mucinous & ADK, NOS \\
\hline 3 & Mucinous & Mucinous-signet ring \\
\hline 4 & NOS & ADK, NOS \\
\hline 5 & NOS & ADK, NOS \\
\hline 6 & NOS & ADK, NOS \\
\hline 7 & NOS with mucinous component & Mucinous component \\
\hline 8 & NOS & ADK, NOS \\
\hline 9 & NOS & ADK, NOS \\
\hline 10 & NOS & Mucinous component \\
\hline 11 & NOS & ADK, NOS \\
\hline 12 & NOS & ADK, NOS \\
\hline 13 & NOS & ADK, NOS \\
\hline 14 & NOS & Mucinous component \\
\hline 15 & NOS & ADK, NOS \\
\hline 16 & ADS & Nonkeratinizant squamous component \\
\hline 17 & NOS & ADK, NOS \\
\hline 18 & NOS & ADK, NOS \\
\hline 19 & NOS & ADK, NOS \\
\hline 20 & NOS & ADK, NOS \\
\hline 21 & NOS & ADK, NOS \\
\hline 22 & NOS & ADK, NOS \\
\hline 23 & NOS & ADK, NOS \\
\hline 24 & NOS & ADK, NOS \\
\hline 25 & Signet ring; mucinous & Mucinous component \\
\hline 26 & Signet ring; mucinous & Mucinous component \\
\hline 27 & NOS & ADK, NOS \\
\hline 28 & NOS & ADK, NOS \\
\hline 29 & NOS & ADK, NOS \\
\hline
\end{tabular}

\section{Discussion}

Cutaneous cancer metastases are a rare event, occurring in about $1.3 \%$ of cases at the time of presentation of the primary tumor [4]. The insurgence of cutaneous metastasis is infrequently described as the first sign of malignancy in CRC and occurs with greater frequency in breast and lung carcinoma, followed by kidney and ovarian cancer $[1,5,9,10]$. Moreover, cutaneous metastasis arising before visceral metastasis is an extremely unusual occurrence in CRC [4]. Therefore, due to the uncommon nature of this entity, the correct identification of cutaneous metastasis with dermoscopy is very hard, leading to misdiagnosis and underreporting of cutaneous metastasis clinical suspicion [11].

Very little is known about timing correlation between cutaneous metastases and CRC onset and visceral metastases from CRC onset, due to only case report about number and anatomical localization of skin metastases from CRC reported in Literature.

In current scenario, we described a series of 29 cases of cutaneous metastases from $\mathrm{CRC}$ with special concerns regarding the number, anatomical localization, and time of onset with respect to CRC diagnosis and visceral metastases. Moreover, some considerations regarding the histological features were discussed.

In line with previous findings, our results confirm that the most frequent anatomic localizations of cutaneous metastasis resulting from CRC is abdomen followed by thoracic, facial skin, and perineum localization [2,4]. Interestingly, we observed that almost half of the cases are synchronous respect to CRC onset and that almost half are synchronous to visceral metastases. Furthermore, the most frequent presentation pattern of cutaneous metastases that was observed is represented by a single lesion (70\%) compared to multiple lesions (30\%). Remarkably, all facial skin and thoracic metastases arose as single lesions, and 
this finding might mislead the clinical hypothesis. In fact, clinical suspicion of metastasis resulting from CRC was only raised in two out of five cases of lesions with facial skin localization. In the other three cases, primitive cutaneous tumors (epithelioma and adnexal tumor) and no clinical suspicions were reported. In four out of six lesions with thoracic localization, clinical suspicion of metastases was reported; in the other two cases, no clinical hypothesis was advanced. Moreover, two cases of facial skin lesions were synchronous to CRC, with clinical presentation as epithelioma in one case and without clinical suspicion in the second case. Four cases of thoracic localization were synchronous to CRC, only two of which being hypothesized as metastasis from CRC, whereas in the remaining two cases, no clinical information was available. Interestingly, of the three facial skin metastases from CRC described in the literature $[6,12,13]$, only one was synchronous to CRC diagnosis [12]. Of note, no study concerning thoracic cutaneous localization from CRC has been reported. Thus, these findings underline the importance of ensuring that an indepth clinical information is requestion when submitting cutaneous lesions for histological evaluation. In fact, a single lesion is not usually clinically suspected of metastasis, and primitivity is suspected close to the anatomic localization of cutaneous lesions, such as lung cancer and breast lesions in case of thoracic localization.

Localization and the time of onset of cutaneous metastasis from CRC with respect to visceral metastases have been never described in detail. Skin metastases have only been described in a synchronous or metachronous timeframe with respect to visceral metastases, and in patients with no visceral metastases, skin lesions were found exclusively on the abdominal wall or perineum [6,12]. Intriguingly, of our 15 patients with visceral metastases notice, 3 cases of cutaneous metastases arose before visceral metastases, 7 were synchronous, and 5 were metachronous to visceral metastases. One of three cases arising before visceral metastasis was located in facial skin, and one in the thoracic skin, respectively.

Finally, from a histological point of view, peculiar aspects of the cutaneous metastases described in this study should alert pathologists. In fact, we observed a squamous cheratinizant malignant component in a single lesion in facial skin in a patient without oncological anamnesis. The squamous component can be observed in primitive skin tumors, either epithelial and/or adnexal, confounding diagnosis. In our series, all cases with a mucinous and/or signet ring component were located in abdominal skin. Being that single cutaneous metastases often favor the closest primitivity [4], in a single thoracic lesion with a mucinous component at histological examination, a pulmonary primitivity can be more reasonably suspected with respect to CRC. In these cases, immunohistochemistry is useless because of the same immunophenotype documented in both pulmonary and CRC primitivity (i.e., TTF1 negativity, CK7 negativity, CK20 positivity, CDX2 positivity). Finally, half of the skin lesions were reported as undifferentiated, suggesting the aggressiveness of these tumors.

These results underline the need of an accurate compilation of histological requests and for a deep dermatological evaluation of patients who are undergoing screening or who have already been diagnosed with cancer in order to provide a high level of suspicion regarding the onset of cutaneous lesions, even if they are clinically compatible with benign illnesses. This evaluation also helps to determine appropriate therapy, because cutaneous metastases indicate an advanced and aggressive disease.

Our study has several limitations. Unfortunately, we were not able to study biological profiles of all of the primitive and metastatic lesions to suggest hypothesis regarding the different metastatic potential in different CRC histotypes and time of metastases onset. Further studies are needed to investigate the molecular landscape of CRC-related cutaneous metastasis. Additionally, due to the reduced number of patients and due to the retrospective nature of the study, it is very difficult to find any statistical associations between the histological features of primitive CRC (such as perineural invasion, tumor budding, pattern of invasion, macroscopic appearance) and the correlation with other risk factor (e.g., exposure to sun, smoke, and alcohol consumption). 


\section{Conclusions}

In conclusion, cutaneous metastasis from CRC is a rare but underreported phenomenon, which should not be ignored, as it indicates an advanced and aggressive disease. Cutaneous metastases from CRC could be the first sign of tumor metastases arising before visceral localization and frequently present as 'single' lesions and at an unusual site. Any change in the skin should raise the suspicion of metastases in the correct clinical context, and biopsy is mandatory in patients with a history of cancer. Early diagnosis will be the key element for adequate management, which requires careful physical examination and a carefully filled format for histological examination. Larger prospective studies are required to better understand the biology of cutaneous metastasis.

Author Contributions: Conceptualization, P.P., D.C., and G.I.; methodology, P.P., D.C., and G.I.; validation, L.R.B., G.C., S.C., V.A., and G.I.; formal analysis, P.P., D.C., and V.F.; investigation P.P., L.R.B., G.C., S.C., and G.I.; resources, P.P., D.U., G.D.M., and G.I.; data curation, P.P., G.C., S.C., D.U., and G.D.M.; writing—original draft preparation, P.P., D.C., and G.I.; writing—review and editing, P.P., D.C., L.R.B., V.A., and G.I.; supervision, P.P. and G.I. All authors have read and agreed to the published version of the manuscript.

Funding: This research received no external funding.

Institutional Review Board Statement: Not applicable.

Informed Consent Statement: Not applicable.

Data Availability Statement: Not applicable.

Acknowledgments: We thank to website 'Servier Medical Art' for supporting Figure 1.

Conflicts of Interest: The authors declare no conflict of interest.

\section{References}

1. Faenza, M.; Del Torto, G.; Di Costanzo, P.; Pieretti, G.; Lamberti, R.; Franco, R.; Ferraro, G.A.; Nicoletti, G.F. Large single cutaneous metastasis of colon adenocarcinoma mimicking a squamous cell carcinoma of the skin: A case report. Int. J. Surg. Case Rep. 2019, 56, 96-100. [CrossRef] [PubMed]

2. Wang, D.Y.; Ye, F.; Lin, J.J.; Xu, X. Cutaneous metastasis: A rare phenomenon of colorectal cancer. Ann. Surg. Treat. Res. 2017, 93, 277-280. [CrossRef] [PubMed]

3. Cazzato, G.; Colagrande, A.; Cimmino, A.; De Marco, A.; Romita, P.; Foti, C.; Resta, L.; Ingravallo, G. Cutaneous Metastases from Primary Liver Cancers: The Need for Knowledge and Differential Diagnosis. Life 2021, 11, 559. [CrossRef] [PubMed]

4. Nambiar, S.; Karippot, A. Multiple Cutaneous Metastases as Initial Presentation in Advanced Colon Cancer. Case Rep. Gastrointest. Med. 2018, 2018, 8032905. [CrossRef] [PubMed]

5. Bin Wong, C.Y.; Kalb, R.E.; Zeitouni, N.C.; Helm, M.A.; Helm, T.N. The presentation, pathology, and current management strategies of cutaneous metastasis. N. Am. J. Med. Sci. 2013, 5, 499-504. [CrossRef] [PubMed]

6. Aravind, B.; Kumar, R.; Basnyat, P. Cutaneous metastases secondary to colorectal carcinoma may not be as ominous as previously thought: A case report and review of the literature. BMJ Case Rep. 2013, 2013, bcr2013008556. [CrossRef] [PubMed]

7. World Health Organization (WHO). Classification of Digestive Tumours, 5th ed.; World Health Organization (WHO): Lyon, France, 2019.

8. Amin, M.B. AJCC Cancer Staging Manual, 8th ed.; Springer: Chicago, IL, USA, 2017.

9. Seyfried, T.N.; Huysentruyt, L.C. On the Origin of Cancer Metastasis. Crit. Rev. Oncog. 2013, 18, 43-73. [CrossRef] [PubMed]

10. Krathen, R.A.; Orengo, I.F.; Rosen, T. Cutaneous Metastasis: A Meta-Analysis of Data. South. Med. J. 2003, 96, 164-167. [CrossRef] [PubMed]

11. Chernoff, K.A.; Marghoob, A.A.; Lacouture, M.E.; Deng, L.; Busam, K.J.; Myskowski, P.L. Dermoscopic Findings in Cutaneous Metastases. JAMA Dermatol. 2014, 150, 429-433. [CrossRef] [PubMed]

12. Parente, P.; Covelli, C.; Parrella, P.; Latiano, T.P.; Fiordelisi, F.; Pellico, M.T.; Maiello, E.; Graziano, P. Intestinal adenosquamous carcinoma with a synchronous skin metastasis: A immunohistochemical and molecular analysis. Int. J. Color. Dis. 2020, 35, 337-341. [CrossRef] [PubMed]

13. Hashimi, Y.; Dholakia, S. Facial cutaneous metastasis of colorectal adenocarcinoma. BMJ Case Rep. 2013, 2013 , bcr2013009875. [CrossRef] [PubMed] 